\title{
Adaptability of pullets from cages to a large cage aviary unit system during the initial settling-in period
}

\author{
Liu Yang ${ }^{1,2}$, Qin Tong ${ }^{1,2,3}$, Haipeng Shi ${ }^{1,2}$, Gang Chen ${ }^{1,2,3}$, Zhengxiang Shi ${ }^{1,2,3}$, \\ Weichao Zheng ${ }^{1,2,3}$, Baoming $\mathrm{Li}^{1,2,3 *}$ \\ (1. College of Water Resources and Civil Engineering, China Agricultural University, Beijing 100083, China; \\ 2. Key Laboratory of Agricultural Engineering in Structure and Environment, Ministry of Agriculture and Rural Affairs, Beijing 100083, \\ China; 3. Beijing Engineering Research Center for Livestock and Poultry Healthy Environment, Beijing 100083, China)
}

\begin{abstract}
Pullets often raised in cage system from week 1 to week 13 in China, when transferred to aviary system after, there will be a problem with adapt. A large cage aviary unit (LCAU) system was developed, which allocated with facilities such as ramps to help cage reared hens to adapt to the multi-tier space. To investigate hens' adaptability to the new system, space use over time in the LCAU system during the first 10 days after hens transferred were recorded, instantaneous scan sampling and continuous focal sampling were used to assess the behavior difference of hens between the LCAU and conventional cage (CC) systems. On the first day of arrival, 10.03\% of hens reached the second tier (S2) and the third tier (S3) of the aviary. During the observation period, an average of $2.42 \%$ of hens climbed and stayed at the upper tiers every day. Space allowance on floor of the first tier (S1) increased from $444.62 \mathrm{~cm}^{2} /$ hen $(91 \mathrm{~d})$ to $586.32 \mathrm{~cm}^{2} /$ hen $(100 \mathrm{~d})$, which was more than $540 \mathrm{~cm}^{2} / \mathrm{hen}$ in the CC system. Comfort behaviors in the LCAU system were significantly more than in the CC system $(p<0.01)$ and hens performed more comfort behaviors with the increase of days after transferred. Hens ate and drank less in the LCAU system in the beginning, however, with the increasing use of upper space, hens ate and drank more and more in the LCAU system during the 10 days after transferred from CC system. Consequently, there were no difference of feed behavior between the CC and LCAU systems $(p>0.05)$ on the last 5 days of the whole observing period. The results indicated that hens gradually learned to use the 3-dimensional space in the initial settling-in period and, gained a good welfare condition in LCAU system. Further studies are needed to investigate the three-dimensional preferences and behavior expression in difference period to bridge the gap in knowledge of space use capacity among adult laying hens.
\end{abstract}

Keywords: large cage aviary unit, laying hen, welfare, comfort behaviors, adaptability

DOI: $10.25165 /$ j.ijabe.20181105.3216

Citation: Yang L, Tong Q, Shi H P, Chen G, Shi Z X, Zheng W C, et al. Adaptability of pullets from cages to a large cage aviary unit system during the initial settling-in period. Int J Agric \& Biol Eng, 2018; 11(5): 70-76.

\section{Introduction}

Non-cage housing systems, such as aviaries, are a future trend of laying hens housing system. They provides facilities with large space, providing a great chance for hens to perform normal or natural behavior and improving welfare of the birds ${ }^{[1,2]}$. In Europe, researchers began to study the aviary system in the early $90 \mathrm{~s}^{[22]}$. Research showed that the system performs better in terms of metabolic disease, skeletal health ${ }^{[3]}$, behavior and welfare ${ }^{[4]}$. The United States launched a 3-year project called the Coalition for Sustainable Egg Supply (CSES) ${ }^{[5]}$ from 2012 to comprehensively evaluate three hen housing systems (conventional cage (EC), aviary

\section{Received date: 2017-01-16 Accepted date: $2018-06-20$}

Biographies: Liu Yang, $\mathrm{PhD}$ candidate, research interests: animal housing environment and welfare, Email: yangliucau@cau.edu.cn; Qin Tong, Lecturer, research interests: precision livestock farming and animal welfare, Email: tongqin@cau.edu.cn; Haipeng Shi, PhD candidate, research interests: animal housing environment and welfare, Email: shihaipeng@cau.edu.cn; Gang Chen, Associate Professor, research interests: livestock and poultry environment management technology, Email: chengang@cau.edu.cn; Zhengxiang Shi, Professor, research interests: livestock and poultry environment management technology, Email: shizhx@cau.edu.cn; Weichao Zheng, Associate Professor, research interests: livestock and poultry environment management technology, Email: weichaozheng@cau.edu.cn.

*Corresponding author: Baoming Li, Professor, research interests: livestock and poultry environment management technology, 17 Qinghua Dong Road, Beijing 100083, China. Tel.: 010-62736904, Email: libm@cau.edu.cn.
$(\mathrm{AV})$, and enriched colony (EC)) for egg production ${ }^{[6]}$, with regard to animal behavior ${ }^{[7,8]}$ and well-being ${ }^{[9]}$, environmental impact ${ }^{[10,11]}$ egg safety ${ }^{[12]}$ and quality, food affordability ${ }^{[13]}$, and worker health. Research about the aviary system in China is in the initial stage and few studies has been conducted ${ }^{[14,15]}$. For the ease of management, the vast majority of layer pullets were reared in conventional cage (CC) systems in China. However, when transferring pullets from cages, aviaries are associated with a lack of experience with navigation in a 3-dimensional space, increases the risk of lack of food, water, due to the bad facility utilization of hens ${ }^{[16]}$. Producers are concerned that adaptation of cage-reared hens to the more complicate environment of the aviary system may cause welfare problem for the hens.

In recent years, egg producers are adopting aviaries that provide hens a tiered cage and a litter-covered open floor area. However, particulate matter ${ }^{[17]}$ and ammonia emissions ${ }^{[18,19]}$ in the barn from litter have become a serious problem of aviary system. Aiming at enhancing welfare of hens and mitigating PM emission problem, Key Laboratory of Agricultural Engineering in Structure and Environment at China Agricultural University (CAU) developed the large cage aviary unit (LCAU) system ${ }^{[15]}$ in 2015. The LCAU allocated big colonies, multi-tier floors and facilities such as ramps to help cage reared hens to get assess to upper tiers for activity and rest. Furthermore, nests and perches were installed for laying hens to perform natural behaviors. In the 
LCAU system, multi-tier raised netting floor was used as the ground of hens, no litter was provided such that the PM emission problem is minimized.

The behavioral changes of animals are considered as an indicator of adaptability to the environment ${ }^{[20]}$. If hens are motivated to perform certain kinds of behaviors but are unable to express them due to housing constraints, welfare concerns arise ${ }^{[21]}$. Conventional cages are most often been criticized for restricting the behavior of hens over aviary and other kind of housing systems ${ }^{[22]}$. Comfort behavior is defined as behavior performed by hens to keep themselves comfortable and to escape from an unpleasant state, these behaviors can also help to maintain good feather condition ${ }^{[23]}$. A number of activities of laying hens have been grouped and termed "comfortable behavior". These activities include flap wings, stretch wings, dust bathe, feather rise, preen, scratch self and tail wag ${ }^{[24]}$. Head shake is reported as an alerting response of hens which reflect hens in a condition of anxiety ${ }^{[25]}$. This reported study was to investigate hens' space use, comfort and other kind of behaviors over time in the LCAU systems such that hens' adaptability to the new system may be better understood. More specifically, the objectives of the study were: (i) to reveal space use over time in the LCAU system in the 10 days after transferring; (ii) to compare behavior differences between hens in the LCAU and $\mathrm{CC}$ system in the first ten days; and (iii) to develop a set of recommendations on the design of the aviary housing system when transferring CC reared pullets to the LCAU become a need.

\section{Experiment design}

\subsection{Housing systems and animals}

This study involved the use of 1650 commercial hybrid White Leghorn layers (Yukou Jing Pink I layers, Yukou, Beijing, China). All the hens were hatched and reared in a commercial farm until 13 wk of age. All of the hens were reared in the same barn equipped with conventional cages. The rearing cage dimension is $65 \mathrm{~cm} \times 60 \mathrm{~cm} \times 40 \mathrm{~cm}(\mathrm{~L} \times \mathrm{W} \times \mathrm{H})$, eight hens/cage with $487.5 \mathrm{~cm}^{2}$ floor area and $8 \mathrm{~cm}$ feeder space/pullet. At the age of $90 \mathrm{~d}$, the hens were transferred to the experimental barn of the Key Laboratory of Agricultural Engineering in Structure and Environment. The hens were randomly divided into two groups, 1350 hens were transferred to the LCAU system, the other 300 hens to the CC systems. The LCAU system (Figure1) has a big space of $600 \mathrm{~cm} \times 300 \mathrm{~cm} \times 330 \mathrm{~cm}(\mathrm{~L} \times \mathrm{W} \times \mathrm{H})$ per unit, there were three duplicated units of the whole system with 450 hens housed in each unit. Stocking density in the LCAU system was $986.6 \mathrm{~cm}^{2}$ of total floor area per hen $(8 \mathrm{~cm}$ feeder space per hen). The LCAU has multi-tier raised netting floor, and other components such as ramps to help young hens to get assess to upper tiers, nests and perches. The feeding troughs and nipple drinkers were the similar type with the rearing phase (Figures 1 and 2).

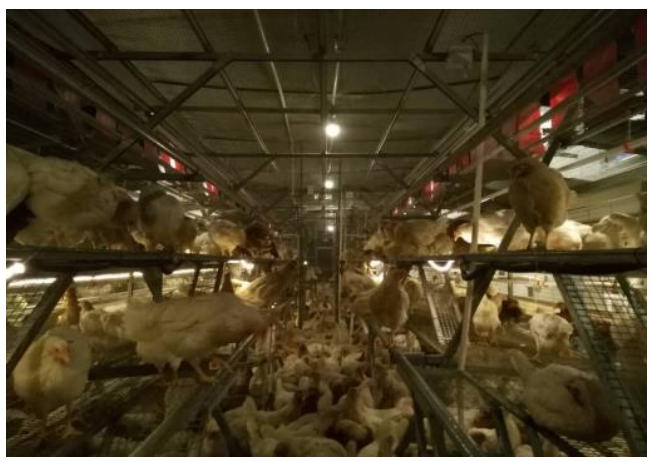

Figure 1 LCAU system

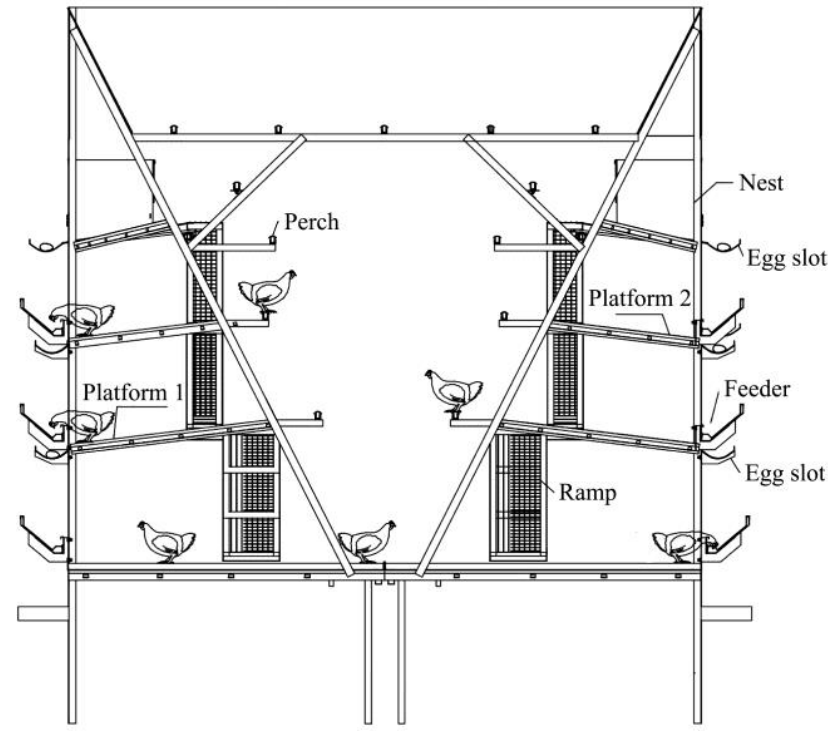

Figure 2 LCAU system (an elevated mesh-wire floor and two platforms at two heights, ramps between floor and platforms to help hens get assess to different tiers easily)

The ramps were in $85 \mathrm{~cm} \times 27 \mathrm{~cm}(\mathrm{~L} \times \mathrm{W})$, with the angle of $50^{\circ}$. The distance between the elevated mesh-wire floor and platform 1 was $55 \mathrm{~cm}$ in height; the distance between the first platform and the second platform was $50 \mathrm{~cm}$ in height. Each unit of the LCAU system was visually divided into three tiers (Figure 2): the lowest mesh-wire floor to the floor of platform1 (S1), the floor of platform 1 to the floor of platform 2 (S2), above the floor of platform 2 (S3); each unit was $6 \mathrm{~m}$ long, and the ramps were located at every $2 \mathrm{~m}$. During the experimental period, very few hens perched of the top floor, therefore, analysis was mainly focused on the use of the lower three floors.

The CC system (Figure 3) was conventional three tiers battery cages $(45 \mathrm{~cm} \times 60 \mathrm{~cm} \times 45 \mathrm{~cm}, \mathrm{~L} \times \mathrm{W} \times \mathrm{H})$ without any enrichment such as perches or laying nests. There were 60 reduplicated cages, 5 hens in each cage. In CC system, the stocking density was $540 \mathrm{~cm}^{2}$ floor area per hen with $9 \mathrm{~cm}$ feeder space per hen. All cages were considered as one experimental unit in instantaneous scanning observation.

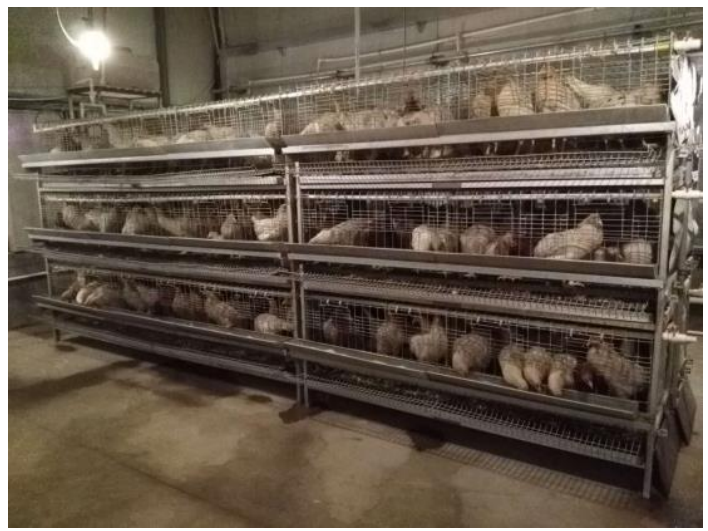

Figure 3 CC system

The hens were provided water and food ad-libitum via nipple drinkers and metal feeders troughs, which were the same to that of the rearing farm in both systems. During the experiment period, the photoperiod was $9.5 \mathrm{~h}$ from 7:00 to $16: 30$.

\subsection{Behavioral observations}

During the $10 \mathrm{~d}$ housing phase after transfer, direct behavioral observations using instantaneous scanning techniques and focal sampling ${ }^{[26]}$ were conducted for $3 \mathrm{~h} / \mathrm{d}$ in the mornings (from 9:00 to 
12:00) and afternoons (from 13:00 to 16:00), respectively.

Instantaneous scanning was at the beginning of each observation time blocks. The number of hens perform each kind of behavior (Table 1) in each 15 min interval at each location was recorded. Each aviary units and conventional cages was observed in a random order, and scanned 6 times per day, and the data were averaged.

Table 1 Ethogram of instantaneous scan sampling

\begin{tabular}{|c|c|}
\hline Behavior & Description \\
\hline Feed & Ingestion of commercial feed ration \\
\hline Drink & Intake of water from hanging drinkers in cage or pen \\
\hline Comfort behaviors & All the comfort behavior described by Table 2 \\
\hline Feather pecking & Pecking at own or cage mate's plumage \\
\hline Resting and other & $\begin{array}{l}\text { No apparent movement of any part of the body or } \\
\text { not involved in any of the above patterns }\end{array}$ \\
\hline
\end{tabular}

Focal sampling observations were taken after the instantaneous scanning using the ethogram described in Table 2. The frequency of hens performed each kind of behavior in both systems has been recorded. The whole unit of the LCAU system was divided into four different functional areas, i.e., the floors near or away from feeding and drinking facilities, the perches, and the ramps. With each functional area, observation plots $\left(1 \mathrm{~m}^{2}\right)$ were selected randomly for each session. The observed cages of the CC system were selected randomly. Each observation was started with $5 \mathrm{~min}$ to walk to the observation plot and, after a 5 min adaptation period, hens were selected and observed for $5 \mathrm{~min}$ continuously ${ }^{[26]}$. Sixteen hens were observed per day in each system. When the selected hen moved out of sight, the chicken immediately to its right as observed from the observer's viewpoint became the focal subject and observed for the remaining time.

\section{Table 2 Ethogram of continuous focal sampling}

\begin{tabular}{|c|c|}
\hline Behavior & Description \\
\hline \multicolumn{2}{|r|}{ Comfort behavior } \\
\hline Flap wings & Bilateral wing movement including wing raising \\
\hline Stretch wings & $\begin{array}{l}\text { Unilateral backward and downward stretching of leg and wing } \\
\text { together }\end{array}$ \\
\hline Dust bathe & $\begin{array}{l}\text { Lie on side, scratch at cage floor, rub head and neck on floor, } \\
\text { open wings }\end{array}$ \\
\hline Feather raise & $\begin{array}{l}\text { Raise feathers with or without rigorous rotation of body around } \\
\text { axial plane, subsidence of feathers back to smooth position }\end{array}$ \\
\hline Preen & Raise feathers and clean or realign them with beak \\
\hline Scratch self & $\begin{array}{l}\text { Leg brought upwards and forwards under wing to scratch } \\
\text { lowered head }\end{array}$ \\
\hline Tail wag & Rapid sideways movement of tail \\
\hline
\end{tabular}

\begin{tabular}{cl}
\hline Alert behavior \\
\hline Shake head & $\begin{array}{l}\text { Rapid rotary movement of head, accompanied by slight raising } \\
\text { of head and neck feathers }\end{array}$
\end{tabular}

Besides behavior observation, 30 birds were randomly selected from each housing system and weighed individually at the $5^{\text {th }}$ and $10^{\text {th }}$ day.

\subsection{Statistical analyses}

Statistical analyses were conducted using SPSS 22.0 $0^{[27]}$. For the LCAU system, scan sampling data of the 3 units were averaged. Subsequently, the percentage of each type of behaviors was calculated per unit. For the CC system, scan sampling data of each cage were summed for further analysis. Difference of behavior occurrence between these two housing systems was compared. The statistical significance was accepted at the probability level less than $5 \%$.

\section{Results and Discussion}

\subsection{Space use over time in the LCAU system}

On the first day of arrival, $10.03 \% \pm 1.7 \%$ of hens reached the upper tiers (S2 and S3), mostly because birds started to use the lower ramps on the day they arrived. During the observation period, an average of $2.42 \% \pm 0.5 \%$ of hens climbed and stayed on the upper tiers every day (Figure 4). As a result, $31.78 \% \pm 7.9 \%$ of hens stayed on the floors of S2 and S3 on the $10^{\text {th }}$ day.

In this reported study, food and water were been provided each tiers of the system. Hens were put on to the floor of S1 when they arrived to reduce incidence of fall. In the literature, it was reported that given enough space, hens had a trend to choose to remain low within pens ${ }^{[28]}$. However, in this study, it was observed that hens had to move up to get enough feed, water, and space to rest. Thus they learned to wing assisted incline running on the ramps and stayed on the higher floors.

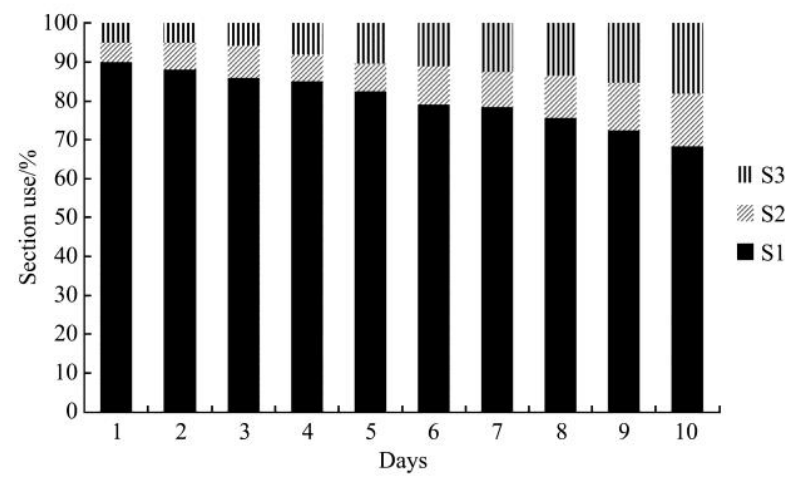

Note: S1: elevated mesh-wire floor to the floor of platform 1; S2: the floor of platform1 to the floor of platform 2; S3: above the floor of platform 2 Percentages were calculated from a total of 6 behavioral counts per day.

Figure 4 Percentage of hens in different space in the LCAU system

Many animals have ability to move up slopes, climb steep branches to protect themselves from predators, or to get food ${ }^{[29,30]}$. Hens climb up to elevated space mainly to escape predators ${ }^{[31,32]}$. Our record was partly agree with Kozak et al. ${ }^{[28]}$, who tested the use of space by pullets housed in complex aviaries, found hens preferred to the ground from the age of wk1 to the age of wk9. The high density on the ground of S1 in our research may cause a pressure of hens to found more food and other resources, which lead to the final increase of upper space use. Cage reared hens lack of experience of aerial space use, making them harder to fly to the perch or edge of mesh floor above, which may cause discourage use for the S2 and S3.

Space allowance on floor of S1 increased from $444.62 \mathrm{~cm}^{2} /$ hen (91 d) to $586.32 \mathrm{~cm}^{2} /$ hen $(100 \mathrm{~d})$, which is more than in the CC system. In the CC system, the housing density is $540 \mathrm{~cm}^{2}$ floor area per bird. The EC standards $1999^{[33]}$ regulates that stocking density must not less than $1111 \mathrm{~cm}^{2}$ floor area per bird in alternative systems, and not less than $570 \mathrm{~cm}^{2}$ floor area per bird in enriched cage systems. To our observing, after one month, the hens evenly distributed in three tires spaces. Floor area per bird in the LCAU system then was $986.6 \mathrm{~cm}^{2}$, a lot more than that in enriched cage system, however, a little less than that in alternative systems.

Space allowance will influence behaviors such as feeding, drinking and resting ${ }^{[34]}$. Social disturbance may affect the feeding bout length at higher stocking densities, to our record, hens climbed to higher space means they can have chance to get sufficient resource with less disturbance. That provides greater freedom for 
comfort behaviors such as wing flapping, stretching, body shaking, and tail wagging, a relatively large amount of space is required.

\subsection{Frequency of behavior performed by focal sampling}

A total of 320 birds were recorded over the course of the study for the collection of different kinds of behavior data in $10 \mathrm{~d}$. All kinds of behaviors listed in the behavior ethogram, were observed in both housing system.

There was a significant difference of comfort and aversion behavior between the LCAU and the CC systems (Figure 5). Flap wings $(p<0.01)$, tail wag $(p<0.001)$ and Scratch self $(0.01<p<0.05)$ were performed more in the LCAU system.

Flapping wings and tail wag, seldom occurred in the CC system, suggests that the cage frustrates these kind of behavior because the space is limited. Behaviors especially wing flapping probably have benefit in addition to increase hen's body comfort ${ }^{[35]}$. Comfort behavior happened more frequently and increase with days after transferred to the LCAU system than to CC system, this agrees with the observation by Taylor and Hurnik ${ }^{[36]}$, which may owing to the result of extension of space use. Studies revealed that alternative systems engage in a wide variety of behavior patterns ${ }^{[37-39]}$. Agreeing with reports, comfort behaviors in the present study were observed more in the LCAU than in the CC systems, even just after introduction.

Increasing of head-shaking behavior reflect a higher level of anxiety $^{[40]}$. There was no significant difference between these two systems regarding this behavior, indicating that LCAU system did not bring more anxiety stress to birds.

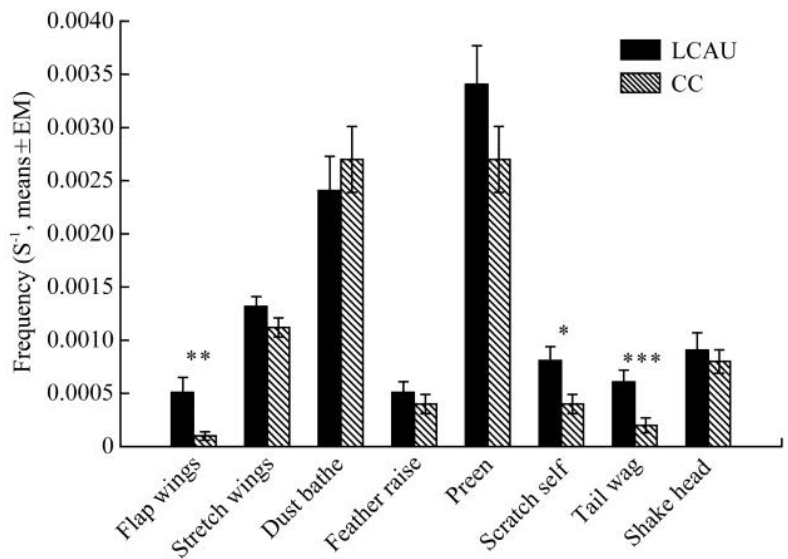

Note: $* p<0.05, * * p<0.01, * * * p<0.001$, measured by continuous focal sampling. Frequencies were calculated from a total of observation 320 birds, $n_{\mathrm{cc}}=n_{\mathrm{LCAU}}=$ 160 hens. Each error bar represents standard deviation of the 160 behavioral counts.

Figure 5 Frequency of different behaviors in LCAU and CC system

\subsection{Percentage of hens of different behaviors by} instantaneous scan sampling

The numbers of hens performing the scheduled activities (Table 1) in both systems have been recorded and analyzed. Subsequently, the percentage of hens performing each of 5 categories of behaviors was calculated in both systems. The proportion of hens performed each kind of behavior reached a status of relative balance faster in CC system than in the LCAU system, different kinds of behavior performed by days and body weight of hens are shown in Figures 6-11).

ANOVA analysis of instantaneous scan sampling data result in a significant difference drinking, comfort, feather pecking behaviors between both housing systems. Feeding (Figure 6, $p>0.05$ ), resting and others (Figure 10, $p>0.05$ ) were not performed difference in both housing system. Drinking (Figure 8 , $p<0.0001$ ) and comfort (Figure 9, $p<0.001$ ) were performed significantly more in the LCAU system. Feather pecking $(p<0.01)$ was performed significantly more in the $\mathrm{CC}$ system in the first $10 \mathrm{~d}$.

\subsubsection{Feeding behavior and bodyweight}

The number of hens who performed the behavior of feed increased day by day, which resulted in the change of growth rate (Figure 6). Amgarten and Mettler ${ }^{[41]}$ found lower feed consumption per bird per day in aviaries compared to battery cages. The relationship between body weight and welfare is not self-evident, but it depends on the condition of the hens other index of health. It is very important that a mature pullet body weight is attained before pullets are stimulated into production ${ }^{[42]}$. Cloacal region was more affected by lesions in birds with a higher weight, especially in the beginning of production period. All birds in both systems had ad libitum access to feed, the physical activity allowed by the relatively more enriched environment in LCAU system is thought to affect the behavior of feed, so as to contribute to the higher feed consumption and lower body weight of the aviary hens. These results confirm previous findings by Taylor and Hurnik ${ }^{[36]}$ and Nørgaardnielsen ${ }^{[43]}$.

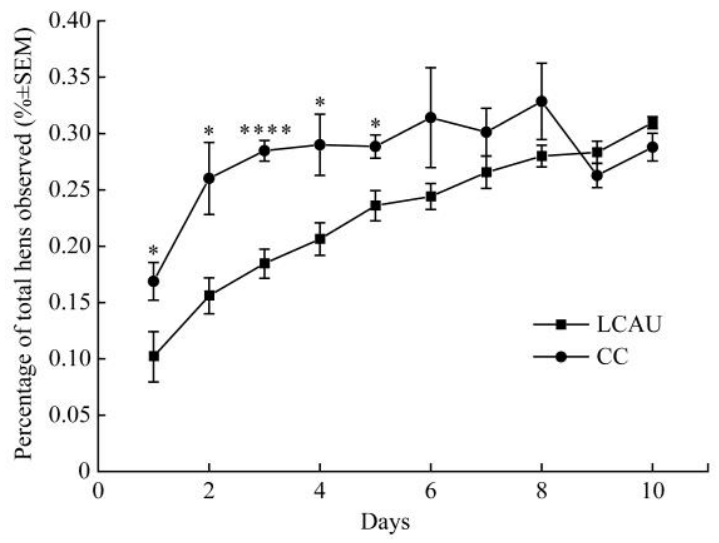

Note: $* p<0.05, * * * * p<0.0001$, measured by instantaneous scan sampling Percentages were calculated from a total of 6 behavioral counts per day. Each error bar represents standard deviation of the 6 behavioral counts per day.

Figure 6 Percentage of time spent on feed behaviors in LCAU and CC system

The average weight of laying hens on the first day was $1208 \mathrm{~g}$, and the weight uniformity was $100 \%$, which was allocated to two systems randomly. Body weight of hens in the LCAU system on the $5^{\text {th }}$ day was significantly less than that of CC system $(p<0.0001)$ (Figure 7). Hens in the CC system were $103.25 \mathrm{~g}$ more than in the LCAU system. On the $10^{\text {th }}$ day, although there were also significant $(p<0.003)$, the gap among the two systems changed to $75.17 \mathrm{~g}$

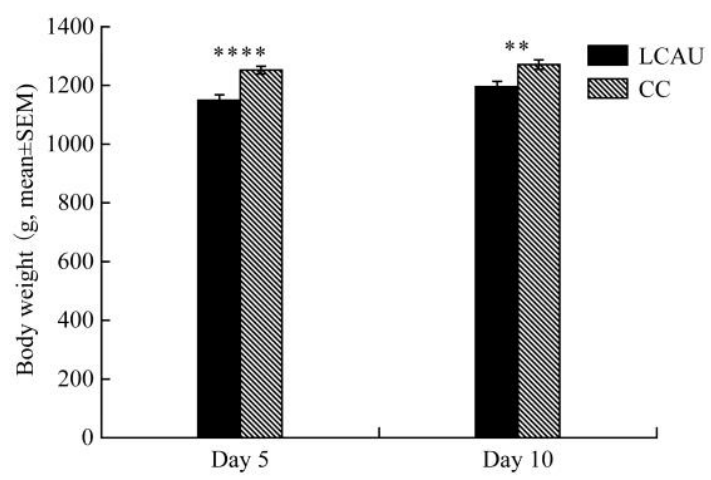

Note: $* * p<0.01, * * * * p<0.0001 . \quad n_{\mathrm{cc}}=n_{\mathrm{LCAU}}=30$ at each day. Each error bar represents standard deviation of the body weight of 30 birds in each group.

Figure 7 Body weight in LCAU and CC systems 


\subsubsection{Drinking behavior}

In this study, hens performed less drink behavior in LCAU system (Figure 8) than in the CC system during the observed time, in part of this may be due to the birds spending more time on other activities. Because of the environmental complexity of the LCAU system, hens spent more time exploring the new facilities instead of resting or doing other things, it also made them drink less. In the CC system, the water line located at the front of the cage, just near the gate, above the feed through, thus birds could easily reach the water line during or after they ate. In the LCAU system, water line located at $40 \mathrm{~cm}$ behind the gate, when a hen felt thirst during eating, it had to walk back to drink. For competing of feed resources, it was prone to choose to stay at the feed through and then spent a longer time on drinking. The chance of being disturbed by others during drinking in LCAU system was also greater than in the $\mathrm{CC}$ system.

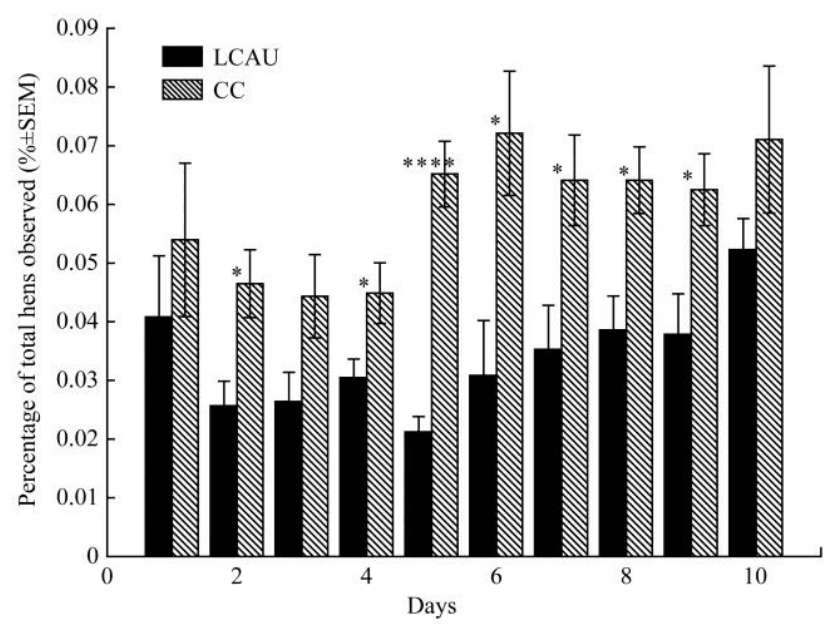

Note: $* p<0.05, * * * * p<0.0001$, measured by instantaneous scan sampling Percentages were calculated from a total of 6 behavioral counts per day. Each error bar represents standard deviation of the 6 behavioral counts per day.

Figure 8 Percentage of time spent on drink behaviors in LCAU and CC systems

\subsubsection{Comfort behaviors}

The higher percentage of hens in the LCAU system performed comfort behaviors (Figure 9), agreeing with the results by continuous focal sampling, which gives a second illustration of good welfare of hens in the LCAU system. Comfort behaviors increased greatly in the last 5 days of the experiment period, because more use of the upper tier by hens. Comfort behaviors, such as flap wings and stretching, were less in the CC system probably because the limited cage height constrained these of behavior patterns ${ }^{[44]}$. In other words, more vertical and three-dimensional space in the LCAU system gave layers the opportunity to express more types of comfort behaviors, resulting in more chicken expression comfort than the $\mathrm{CC}$ system at the same time.

\subsubsection{Feather pecking}

Feather pecking was less $(<0.2 \%)$ in the LCAU system than in the CC system $(0.15 \%-3.2 \%)$ (Figure 10$)$. It was similar to the result of Tanaka and Hurnik ${ }^{[44]}$, which hens feather pecking more in the CC $(4.1 \%)$ system than in the AV $(<0.1 \%)$ system when the hens were transferred from floor pens to $\mathrm{CC}$ and $\mathrm{AV}$ system in the first two weeks. Less aggressive behavior was found in the LCAU system than in the CC system during the observing period, reflected by differing amounts of feather pecking. Hens in the CC system were forced to be close to each other and the environment was restricted, however, in the LCAU system, hens access to enrichment or resources was probably a help of escape to be pecked $^{[46]}$. Hens were able to withdraw from potential interaction in three dimensions is a possible reason for the aggressive interactions per bird was lower in the LCAU system ${ }^{[47]}$.

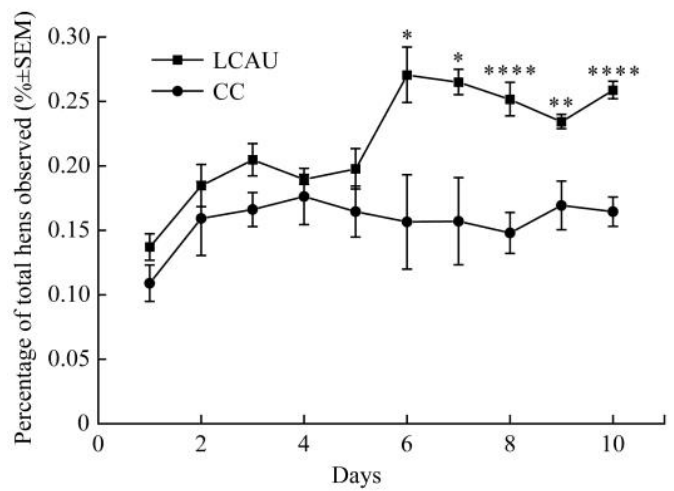

Note: $* p<0.05, * * p<0.01$, **** $p<0.0001$, Measured by instantaneous scan sampling. Percentages were calculated from a total of 6 behavioral counts per day. Each error bar represents standard deviation of the 6 behavioral counts per day.

Figure 9 Percentage of time spent on comfort behaviors in LCAU and CC systems

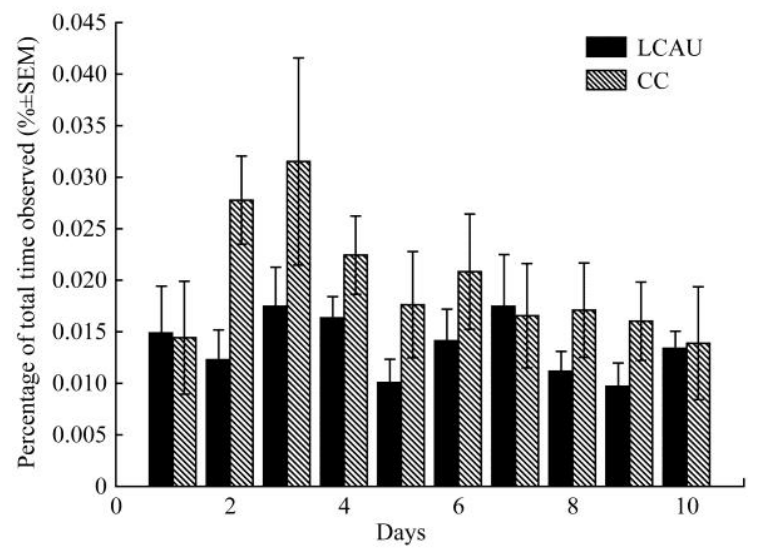

Note: Measured by instantaneous scan sampling. Percentages were calculated from a total of 6 behavioral counts per day. Each error bar represents standard deviation of the 6 behavioral counts per day.

Figure 10 Percentage of time spent on feather pecking behaviors in LCAU and CC systems

\subsubsection{Rest and other behaviors}

The average proportion of rest and other behaviors in the cages was slightly higher in the LCAU system at the beginning, but less than in the CC system in the last 4 days (Figure 11). Proportion

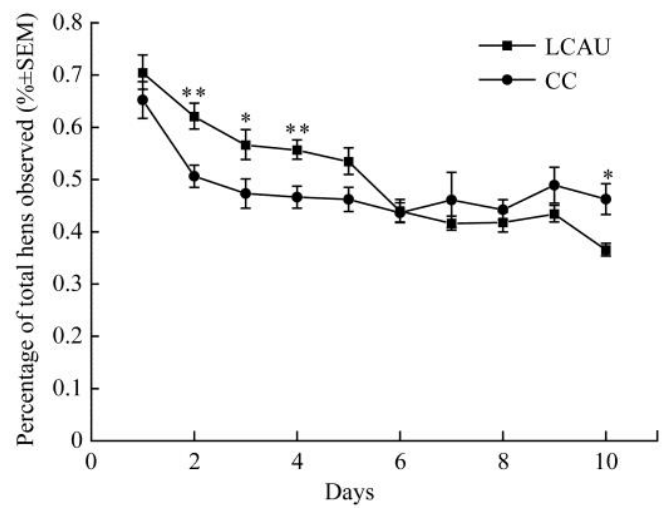

Note: $* p<0.05, * * p<0.01$, measured by instantaneous scan sampling. Percentages were calculated from a total of 6 behavioral counts per day. Each error bar represents standard deviation of the 6 behavioral counts per day.

Figure 11 Percentage of time spent on rest and other behaviors in LCAU and CC system 
of this kind of hens in the CC system was relatively stable, but in the LCAU system, with the hens go up to the upper space, hens spent their time on explore the new environment and perform more time on feed, drink and comfort behavior, thus less and less hens perform rest and other behaviors.

\section{Conclusions}

The newly designed LCAU provided a good facility for hens. The hens learned to use ramps to get to the multi-tier floor to get feed and water even in the first day and increased gradually in the LCAU system. The results of this research have revealed a preliminary exploration of equipment design effects on welfare during the initial settling-in period in aviary systems. In general, the performance of comfort behaviors in LCAU systems was relatively high and some specific behaviors, namely flapping wings and tail wag, seldom to occur in the CC system. Well-designed aviary system provided a good environment for hens to adapt to the new housing system. The design of the system and in particular the number and style of ramps, the distribution and ease to get the resources must be monitored more closely in future studies. Further studies are needed to investigate the three-dimensional preferences and behavior expression in difference periods to bridge the gap in knowledge of space use capacity among adult laying hens.

\section{Acknowledge}

The authors wish to acknowledge the financial support of the Beijing Science \& Technology Commiittee Special Project (Z171100002217018), China Agricultural Research System (CARS-40), and Natural Science Foundation of China (31601981). The authors would also like to thank Beijing Huadu Yukou Poultry Industry Co., Ltd., Beijing, 10126, China, for the help of hen's management.

\section{[References]}

[1] Lay D C, Fulton R M, Hester P Y, Karcher D M, Kjaer J B, Mench J A, et al. Hen welfare in different housing systems. Poultry Science, 2011; 90(1): 278-294.

[2] Campbell D L M, Makagon M M, Swanson J C, Siegford J M. Perch use by laying hens in a commercial aviary. Poultry Science, 2016; 95(8): 1736-1742.

[3] Leyendecker M, Hamann H, Hartung J, Kamphues J, Neumann U, Sürie C, et al. Keeping laying hens in furnished cages and an aviary housing system enhances their bone stability. British Poultry Science, 2005; 46(5): 536 .

[4] Blokhuis H J, Fiks V N T, Bessei W, Elson A, Guémené D, Kjaer J B, et al. The Laywel project: Welfare implications of changes in production systems for laying hens. Worlds Poultry Science Journal, 2007; 63(1): 101-114.

[5] Zhao Y, Shepherd T A, Swanson J C, Mench J A, Karcher D M, Xin H. Comparative evaluation of three egg production systems: Housing characteristics and management practices. Poult Sci, 2015; 94(3): 475.

[6] Karcher D M, Jones D R, Abdo Z, Zhao Y, Shepherd T A, Xin H . Impact of commercial housing systems and nutrient and energy intake on laying hen performance and egg quality parameters. Poult Sci, 2015; 94(3): 485-501.

[7] Campbell D L, Makagon M M, Swanson J C, Siegford J M. Litter use by laying hens in a commercial aviary: Dust bathing and piling. Poult Sci, 2016; 95(1): 164-175.

[8] Campbell D L M, Makagon M M, Swanson J C, Siegford J M. Laying hen movement in a commercial aviary: Enclosure to floor and back again. Poult Sci, 2016; 95(1): 176.

[9] Blatchford R A, Fulton R M, Mench J A. The utilization of the Welfare Quality® assessment for determining laying hen condition across three housing systems. Poult Sci, 2016; 95(1): 154-163.
[10] Zhao Y, Shepherd T A, Li H, Xin H. Environmental assessment of three egg production systems-Part I: Monitoring system and indoor air quality. Poult Sci, 2015; 94(3): 518-533.

[11] Shepherd T A, Zhao Y, Li H, Stinn J P, Hayes M D, Xin H. Environmental assessment of three egg production systems - Part II: Ammonia, greenhouse gas, and particulate matter emissions. Poult Sci, 2015; 94(3): 534-543.

[12] Jones D R, Cox N A, Guard J, Fedorka-Cray P J, Buhr R J, Gast R K, et al. Microbiological impact of three commercial laying hen housing systems. Poult Sci, 2015; 94(3): 544-551.

[13] Matthews W A, Sumner D A. Effects of housing system on the costs of commercial egg production. Poult Sci, 2015; 94(3): 552.

[14] Zheng H, Li B, Chen G, Wang C Y. Improving utilization of nests and decreasing mislaid eggs with narrow width of group nests. Inter J Agric \& Biol Eng, 2018; 11(1): 83-87.

[15] Yang L, Li B. Research progress of welfare-oriented breeding mode and technical equipments for laying hen. Transactions of the CSAE, 2015; 31(23): 214-221. (in Chinese)

[16] Janczak A M, Riber A B. Review of rearing-related factors affecting the welfare of laying hens. Poult Sci, 2015; 94(7): 1454-1469.

[17] Zheng W, Zhao Y, Xin H, Li B, Gates R S, Zhang Y, et al. Concentrations and size distributions of airborne particulate matter and bacteria in an experimental aviary laying-hen chamber. Transactions of the ASABE, 2013; 56(6): 1493-1501.

[18] Dekker S E M, Aarnink A J A, Boer I J M D, GrootKoerkamp P W G. Emissions of ammonia, nitrous oxide, and methane from aviaries with organic laying hen husbandry. Biosystems Engineering, 2011; 110(2): 123-133.

[19] Zhao Y, Xin H, Shepherd T A, Hayes M D, Stinn J P, Li H. Thermal environment, ammonia concentrations, and ammonia emissions of aviary houses with white laying hens. Transactions of the Asabe, 2013; 56(3): 1145-1156.

[20] Dawkins M S. The role of behaviour in the assessment of poultry welfare. Worlds Poultry Science Journal, 1999; 55(55): 295-303.

[21] $\mathrm{Cj} \mathrm{N}$. Behavioural needs, priorities and preferences of laying hens. Worlds Poultry Science Journal, 2015; 62(2): 296-307.

[22] Tanaka T, Hurnik J F. Comparison of behavior and performance of laying hens housed in battery cages and an aviary. Poultry Science, 1992; 71(2): 235-243.

[23] Appleby M C, Hughes B O. The Edinburgh modified cage for laying hens. British Poultry Science, 1995; 36(5): 707-718.

[24] Nicol C J. Social influences on the comfort behaviour of laying hens Applied Animal Behaviour Science, 1989; 22(1): 75-81.

[25] Hughes B O. Headshaking in fowls: The effect of environmental stimuli. Applied Animal Ethology, 1983; 11(1): 45-53.

[26] Mollenhorst H, Rodenburg T B, Bokkers E A M, Koene P, Boer J M On-farm assessment of laying hen welfare: a comparison of one environment-based and two animal-based methods. Applied Animal Behaviour Science, 2005; 90(3-4): 277-291.

[27] IBM SPSS Institute Inc, 2013. IBM SPSS Statictics 22.0, User's Guide, IBM SPSS Institute Inc.,

[28] Kozak M, Tobalske B, Martins C, Bowleyc S, Wuerbeld H Harlander-Matauscheka A. Use of space by domestic chicks housed in complex aviaries. Applied Animal Behaviour Science, 2016; 181: $115-121$.

[29] Kraft T S, Venkataraman V V, Dominy N J. A natural history of human tree climbing. Journal of Human Evolution, 2014; 71(2): 105-118.

[30] Stewart F A, Pruetz J D, Hansell M H. Do chimpanzees build comfortable nests? American Journal of Primatology, 2007; 69(8): 930-939.

[31] Drovetski S V. Influence of the trailing-edge notch on flight performance of galliforms. Auk, 1996; 113(4): 802-810.

[32] Dial K P. Evolution of avian locomotion: Correlates of flight style, locomotor modules, nesting biology, body size, development, and the origin of flapping flight. Auk, 2003; 120(4): 941-952.

[33] Directive E U. Council Directive 99/74/EC of 19 July 1999 laying down minimum standards for the protection of laying hens. Official Journal of the European Communities, 1999: 53-57. http://www.abolitionistapproach.com/media/links/p130/european-union.pd f. Accessed on [2017-01-06]

[34] Cooper J J. Evaluation of the effects of cage height and stocking density on the behaviour of laying hens in furnished cages. British Poultry Science, 2007; 48(1): 1-11. 
[35] Nicol C J. Behavioural responses of laying hens following a period of spatial restriction. Animal Behaviour, 1987; 35(6): 1709-1719.

[36] Taylor A A, Hurnik J F. The effect of long-term housing in an aviary and battery cages on the physical condition of laying hens: body weight, feather condition, claw length, foot lesions, and tibia strength. Poultry Science, 1994; 73(2): 268-273.

[37] Freire R, Wilkins L J, Short F, Nicol C J. Behaviour and welfare of individual laying hens in a non-cage system. British Poultry Science, 2003; 44(1): 22-29.

[38] Appleby M C, Hughes B O, Hogarth G S. Behaviour of laying hens in a deep litter house. British Poultry Science, 1989; 30(3): 545-53.

[39] Odén K, Keeling L J, Algers B. Behaviour of laying hens in two types of aviary systems on 25 commercial farms in Sweden. British Poultry Science, 2002; 43(2): 169-181.

[40] Mendl M. Performing under pressure: Stress and cognitive function. Applied Animal Behaviour Science, 1999; 65(3): 221-244.

[41] Amgarten M, Mettler A. Economical consequences of the introduction of alternative housing systems for laying hens in Switzerland// European
Symposium on Poultry Welfare: Tours, France, 11- June, 1989 / Edited by Jean M. Faure and Andrew D. Mills. 1989.

[42] Bestman M, Wagenaar J P. Health and welfare in Dutch organic laying hens. Animals An Open Access Journal from Mdpi, 2014; 4(2): 374-390.

[43] Nørgaardnielsen G. Bone strength of laying hens kept in an alternative system, compared with hens in cages and on deep-litter. British Poultry Science, 1990; 31(1): 81-89.

[44] Tanaka T, Hurnik J F. Research Note: The behavior of young layers during the first two weeks in aviary and battery cages. Poultry science, 1991; 70(2): 404.

[45] Nicol C J. Effect of cage height and area on the behaviour of hens housed in battery cages. British Poultry Science, 1987; 28(2): 327-335.

[46] Hughes B O, Wood-Gush D G. Agonistic behaviour in domestic hens: the influence of housing method and group size. Animal Behaviour, 1977; 25(4): 1056-1062.

[47] Mclean K A, Baxter M R, Michie W. Comparison of the welfare of laying hens in battery cages and in a perchery. Research and Development in Agriculture, 1986; 3: 93-98. 